\title{
Dean Komel
}

\section{Spomin in pomnjenje $v$ Heideggerjevi obravnavi vprašanja o tem, kaj se pravi misliti}

Ključne besede: spomin, pomnjenje, mislenje, Heidegger, govorica, bistvo

\section{DOI: 10.4312/ars.12.2.87-98}

Tematika spominjanja nedvomno sodi k samim predpostavkam filozofije. Spomin ni le ena od ključnih filozofskih tem, temveč je filozofija po svojem bistvu spomin. Vendar se lahko za tako prvenstvo spomina z enako ali še večjo upravičenostjo poteguje umetnost, saj naj bi jo navdihovale Muze, hčerke Mnemozine. Že zavoljo prestiža se takoj javi še zgodovina. In seveda psihologija, saj sposobnost spominjanja velja za eno osrednjih področij njenih raziskav. Tozadevni psihologistični izsledki sežejo na zelo različna področja, od pedagogike do reklamne industrije, od kognitivne tehnologije do farmacevtskih multinacionalk.

Spominjanje nadalje obeležuje verske obrede. Spremlja človeško življenje v krogotoku življenja in smrti. Da bi »ohranjali spomin«, pišemo memoarje, biografije in historiografije, slikamo portrete in avtoportrete, snemamo fotografije in filme, vzdržujemo arhive, postavljamo spomenike in nagrobnike ... Ali pa se preprosto ozremo v preteklost. Smo že zmeraj ozrti vanjo, tako kot smo zazrti v prihodnost. Vendar se zdi, da to vselejšnjo ozrtost v preteklost bolj kot spomin opredeljuje pozaba, ki sicer najbolj pritiče sedanjosti. ${ }^{1}$ Spominjanje izpolnjujejo najrazličnejši pomeni in nameni, predvsem pa to, da bi se izognili praznini pozabe, jo tako rekoč premagali, a dovolj pogosto neuspešno, zaradi česar spominjanju radi pritaknemo »trajnost « in se kot dotikamo »večnosti«. Ali je spomin močnejši od pozabe, ali je pozaba mogočnejša od spomina, bržkone ne bomo nikoli zmogli prav dognati.

Po starogrškem izročilu Mnemozine in Lethe, reka Spomina in reka Pozabljenja, pritekata iz istega izvira. Je njuno soizviranje tudi poreklo misli in izvor uma, ki po filozofskih naukih ne velja le kot določilo človeškosti, pač pa tudi in predvsem boštva? Um velja za božansko zmožnost človeške duše. Vendar um ni isto kot misel, umevanje ni isto kot mišljenje, razumevanje ni isto kot razmišljanje in premišljanje, doumevanje ni isto kot domišljija, izum ni isto kot domislica ali izmislek. Um in mišljenje sta smiselno različna, vendar oba naravnana na smisel. Um ima svoje smiselno izhodišče

1 Odnos med zgodovino, spominom in pozabo podrobneje obravnava Ricoeur, 2000. 
$\mathrm{v}$ zaznavanju, mišljenje $\mathrm{v}$ spominjanju, vendar so umske zmožnosti najtesneje povezane z zapomnjenjem, medtem ko mišljenje zaznamuje dojemljivost. Nous enkrat prevajamo kot »um«, "umnost «, drugič kot »mišljenje«, ne da bi se posebej spraševali, ali je to dosledno ali ne.

Velik del sodobne filozofije, s heideggerjansko linijo na čelu, se odpoveduje umu, kolikor je z njim speta metafizična moč in oblast predstavljanja, hkrati pa se ne odreka misli. Heidegger postavlja mislenje ob bok pesnjenju. Mislenje, ne mišljenja, kolikor slednje označuje nam dano umsko dispozicijo, za katero se zdi, da smo jo sami izumili, če je nismo, jo pa še bomo v obliki umetne inteligence. ${ }^{2}$ Ta bo oziroma je že mnogo pametnejša od nas. Svojo "pamet «črpa iz pomnilnika. Pomnilniška pamet ni pomnjenje, ki je zadolženo izviru spomina in pozabe ter po njem mnogovrstno zaukazano. Tako se boginjo Ateno v Odiseji opeva kot polimetis, premeteno, preudarno, polno pameti, da lahko v mnogočem svetuje človeku. Pomnilniki omogočajo nepregledne množice izračunavanj in preračunavanj, a nikomur ničesar ne izkazujejo - ne človeškosti ne božanskosti. Pomniki se ne morejo hvaliti s super pametjo, zmorejo pa izkazovati hvaležnost vsemu, kar prebiva v prostranstvu sveta. Človek postavlja pomnike, kolikor ni le nadarjen za to in ono spretnost, pač pa tudi obdarjen s tem, da se spominja na ... in ima to, kar spominja na, $\mathrm{v}$ čemer se prepozna tudi um in umetnost. Morda, ker je človek po Hölderlinovi besedi nerazložljivo znamenje. ${ }^{3}$ Za ljudi izrednih dejanj pravimo, da so znameniti. Znamenita niso samo dejanja, temveč tudi stvaritve in stvari. Tako si, recimo, ogledujemo starodavne znamenitosti. Zanimajo nas, kolikor sprejemamo izhajanje in prihajanje od "pamtiveka" in "vekomaj«, kar ne razodeva kakega podleganja arhaičnosti, marveč nagovorjenost od arche kot izvora, začetka, počela večnotrajnosti in vladanja. Kot taka arheologija se je razvila filozofija. Še pred Foucaultem je v novejši filozofiji to pojmovanje uveljavil Edmund Husserl. V fragmentu iz zapuščine, ki datira v trideseta leta prejšnjega stoletja, tako zapiše:

Fenomenološka arheologija, odkopavanje konstitutivnih zgradb, ki so skrite v svojih stavbnih členih, zgradb aperceptivnih / čutnih storitev, ki so pred nami izgotovljene kot izkustveni svet. 'Vpraševanje nazaj' in potem razkrivanje posameznih storitev, ki vzpostavljajo bitni smisel, do zadnjih, archai, da bi od teh navzgor spet lahko ustvarili v duhu samoumevno enotnost tako raznovrstno fundiranih bitnih veljavnosti z njihovim relativno bivajočim. Kakor pri običajni arheologiji: rekonstrukcija, razumevanje v 'cikcaku' (Husserl, 2005, 5). ${ }^{4}$

2 V prevodu Kaj se pravi misliti je zaradi jasne razločitve bitnozgodovinske in topološke osmislitve od psihološke, logične in kognitivne dispozicije mišljenja vpeljana beseda »mislenje«, ki izhaja neposredno iz glagolske osnove »misliti«.

3 "Znamenje smo, nerazložljivo / Brez bolečine smo in skoraj / Smo izgubili govorico v tujstvu“ (Hölderlin, 1978, 106).

4 Glede fenomenološke analize spomina glej sicer: Husserl 1980. 
Tu zarisana »fenomenološka arheologija« seveda še kako zadeva uvodoma podano ugotovitev, da je filozofska misel po svojem bistvu spomin - ne zato, ker je, recimo, Platon nekje zapisal, da je spoznanje spominjanje, pač pa zato, ker samo bistvo misli pripade spominu, je dosegljivo $v$ spomnjenju in zajemljivo $v$ pomnjenju. Misel pride. Misel uide. A niti ne prihaja niti ne uhaja brez bistva - tudi ko je nebistvena ali brezbistvena. Bistveno je dano v misli in z njo, kolikor se podari zmislenje nanj. Ali so »bistva« po svoji »naravi« imanentna ali transcendentna zavesti, je drugotno vprašanje, $s$ katerim imata opraviti spoznavna teorija in ontologija, ki »bistvo« obravnavata kot vsebino misli, ne pa kot zadevo osmislitve. To je uspelo šele sodobni fenomenologiji na podlagi razgrnitve strukture intencionalnosti in njenih smiselnih plasti. ${ }^{5}$

Kaj je to »bistvo«? V filozofiji smo navajeni, da »bistvo«, ki označuje, kaj je nekaj, razločujemo od »biti«, ki označuje, da je nekaj. A ko bi terjali, da se pojasni, na čem je zasnovano razlikovanje med bistvom in bitjo, naletimo na nemajhno, celo ključno filozofsko zadrego. Tako se Aristotelu izkaže »bistvo« aporetično znotraj njegove določitve ousia, »bitnosti«, ki ima poleg drugih tudi pomen »bistva« in »bistvenosti«. Aristotelu se je zdelo potrebno, da to, kar dojemamo kot bistveno, zajamemo tudi v ustrezno jezikovno obliko, vendar je glede tega prišel v škripce, saj je »bistvo« hotel izpeljati iz prefektove oblike glagola einai, »biti«, ki pa v starogrščini umanjka, zato je namislil sestavljenko to ti en einai, dobesedno »to, kar je bilo biti « ${ }^{6}$ Te strukture se je kasneje oprijel vzdevek apriorni perfekt in ga kot takega beležimo še v Biti in času. ${ }^{7}$ Za naše razpravljanje je perfekt zanimiv, kolikor naj bi izražal dejanje, ki je nastopilo v preteklosti, je pa po svojem "roku trajanja « dejavno še $\mathrm{v}$ sedanjosti in prihodnosti. Perfektov hkratni »že» in »še« bistveno napotuje $\mathrm{k}$ pomnjenju in spominjanju.

Najpomembneje pa je, da se povezava med perfektivnostjo in spominskostjo v filozofiji javi s sprostitvijo bistvenega, in to še pred uveljavitvijo razlike med bistvom in bitjo. Ko pravimo, da je nekaj za nas bistveno ali ne, tega gotovo ne mislimo iz kakega razlikovanja med bitjo in bistvom. Še bolj se ta smisel bistvenega izrazi, ko, recimo, ugotavljamo odsotnost bistvenega sploh. Recimo, ko nas tare brezbistvenost našega časa, epohe, dobe, da jo razlagamo kot »nihilistično«. »Bistveno« se v tem pogledu vrednoti kot »temeljno«. Odsotnost bistvenega kot breztemeljnost in ničevost

5 V Filozofiji kot strogi znanosti tako Husserl poudari, da spoznanje bistva »ni nikakršno matter-offact spoznanje, ne obsega niti najprevidnejše trditve o individualnem (recimo naravnem) bivanju. Podlaga ali bolje, izhodiščni akt nekega bistvogledja, npr. zrenja bistva zaznave, spomina, sodbe itd., je lahko zaznava zaznave, spomina, sodbe itd., lahko pa je tudi gola, vendar 'jasna' fantazija, ki kot taka ni nobeno izkustvo, ne dojema nobenega bivanja. Dojemanja bistva se s tem sploh nismo dotaknili; dojetje bistva je gledanje kot zajetje bistva, to pa je ravno drugačno zajetje bistva kot izkušanje« (Husserl, 1991, 26-27).

6 Prim. Aristoteles, 1999, 88, Metaph. 1007a21; podrobneje Sonderegger, 1983; Grgić, 1990.

7 Prim. Heideggerjevo opombo k Biti in času (Heidegger, 1997, 592). 
nas sili, da pomislimo na tisto, kar je izvorno bistveno, kolikor ga seveda »tek stvari« ni odnesel neznano kam. »Pomislenje« na poseben način vključuje spominjanje, in sicer v pogledu neke odsotnosti, ničnosti, ki naj bi jo prestopili. Tako spominjanje na izvorno $v$ bistvu premošča razliko biti in niča. A kaj naj bi tako premoščanje pomenilo? »Misliti« v odlikovanem smislu reminiscence, ki sega preko? Je po svoji spominjajoči (se) bistvenosti presežno?

Po naukih dobršnega dela sodobne filozofije, ki se je drži oznaka »eksistencializem «, je pred mišljenjem bistveno biti. Sem, torej mislim, zapiše Nietzsche v Veseli znanosti. ${ }^{8}$ »Bistvo « tubiti je v njeni eksistenci, zapiše Heidegger v Biti in času. ${ }^{9} \mathrm{~V}$ bistvenem se oglaša smisel eksistence, ki pa ga ne gre kar izenačevati s smislom življenja, prav kolikor $\mathrm{z}$ »eksistenco « mislimo bistveno, predvsem tako, da izrecno pomislimo in zmislimo na to. Prav na to spomni in hkrati opomni Heidegger, ko v predavanjih o vprašanju, kaj se pravi misliti, uvodoma pripomni:

Najpomiselnejše je, da še ne mislimo: še vedno ne, četudi stanje sveta postaja vse pomisljivejše (Heidegger, 2017, 3).

Ugotovitev ne zadeva le eksplicitne »kritike« tega, kar danes je in razodeva »brezmiselnost «, marveč tudi imanenten odnos med mislijo in spominom, ki izstopi v pomisli na najpomiselnejše. S tem se na nov in drugačen način pokaže, da je filozofija po svojem bistvu spomin - ne $\mathrm{z}$ vidika omogočanja spoznanja ali pritegovanja zgodovine, marveč odsotnosti spoznanja in odtegnitve zgodovinskosti v sodobnosti tega, kar je, v tem ko manjka. Zadržati se je treba ravno ob tem »še ne«, in sicer ne tako, da silimo z mišljenjem ali da prisiljujemo k spremembi sveta. "Zadržati se« tu prej pomeni odmaknjenost, ki je pozorna do neke izmaknjenosti. »Zadržati nekaj« je lastnost pomnjenja, a kako zadržati in vzdrževati to, kar (še) ni? Z zadrževanjem in zdržanjem pomisli? Spominskost je skoz in skoz prepredena z ničnostjo, lahko je nična in ničeva, vendar pa to ne zadeva izviranja spomina, ki je, kot smo nakazali, isto s pozabo. Heidegger ga poskusi zajeti z vprašanjem, kaj se pravi misliti, was heißt Denken? Smiselni odtenki nemškega glagola heißt - se pravi, pove, se glasi, se imenuje, pomeni, veli -, ki jih Heidegger sam razvije med predavanji, na poseben način napotujejo na govor in govorico, kolikor ta kaže in celo zaukaže to, kar je. Lahko nam zmanjka besed, kaj potem? To daje misliti. Ostati brez besed nikakor ne pomeni, da smo prikrajšani od nagovora govorice. Prav nasprotno. Govorca najbolj nagovori misel, ko in če molči. Šele v molku zares nastopi smisel in se lahko zmislimo na najpomisljivejše. Nagovor je v nekem posebnem smislu silnejši od govorice - ker je bistven. To, kar je silnejše in močnejše, je bistveno izvornejše. Daje misliti. Zmisli na. 
$\mathrm{V}$ tem pogledu bi morali odnos misli in spomina izvorno motriti znotraj bistvenega dogodevanja govorice same. "Znotraj« pomeni: zunaj vsake filozofije, znanosti in nazora o jeziku. A to se nam zdi čudno in malo prepričljivo. Še bolj verjetno rekla »bistveno dogodevanje«, »bistvovanje« itn. In vendar niso kar »prinujana«, pač pa nujna za samo ubesedenje filozofije, kolikor ga bistveno izkazuje mislenje kot zmislenje. Ni dovolj, da to ubesedenje vzamemo za bistveno, marveč se mora tudi po sebi bistveno izkazati. Celo Jacquesu Derridaju, za katerega ne moremo reči, da je bil slab poznavalec Heideggerja, je ušlo, ${ }^{10}$ da ta posebej v svojih poznih delih uporablja besedo »Wesen« v reklih, kot je Das Wesen der Technik, Das Wesen der Sprache: Die Sprache des Wesens, Das Sprachwesen v glagolskem pomenu, tj. v dogodevnem ubesedenju: kot »bistvovanje« in ne kot »bistvo «. ${ }^{11}$

Kot posebej bistven se ob tem izkaže odnos misli in spomina. To bistvenost mu poklanja tisto, od česar je nagovorjen. Nagovorjenost ne prihaja od koderkoli, marveč se skriva v vzajemnem prehajanju odnosa samega, ki ga izkazuje reklo Denken ist Andenken-Mislenje je zmislenje (Heidegger, 2017, 135). Kot vsak odnos pri Heideggerju nosi tudi bistveni odnos misli in spomni s seboj značaj diference, raznosa (Austrag), na kar je bil posebej pozoren Gianni Vattimo, Heideggerjev slušatelj ter italijanski prevajalec spisa Kaj se pravi misliti? in snovalec filozofskega gibanja »Pensiero debole«, »šibka misel«. Reklo Denken ist Andenken je vzel za moto lastnega premisleka, ${ }^{12}$ vendar se je ob tem bolj oprl na Heideggerjevo razlago Hölderlinove himne Andenken, Spomin oz. Zmislenje (Heidegger, 2001, 75-137) kot na delo Kaj se pravi misliti. V spremnem zapisu k slovenskemu prevodu tega dela (Heidegger, 2017) sem posebej opozoril na pomanjkljivo recepcijo ključnih konceptualnih premikov v njem (Komel, 2017, 237242). V recenziji prevoda pa sem poskusil razgrniti miselni kontekst tega, kar danes je, sodobnost naše dobe, v kateri Heidegger postavi vprašanje, kaj »je misliti« (Komel, 2018). Razlog za to, da je v bistvenem izostala tudi podrobna obravnava odnosa misli in spomina, deloma tiči tudi v tem, da artikulacija tega odnosa odstopa ne samo od običajne, ampak tudi filozofske govorne rabe. Tako samodejno nastopi vprašanje, na kaj se to, kar Heidegger pove, nanaša. Kje je mogoče najti referenco za povedano? „Do tega, kaj se pravi misliti, dospemo, če sami mislimo« (Heidegger, 2017, 11). Vendar nam Heidegger že ob uvodni ugotovitvi, kako je najpomisljivejše to, da še ne mislimo, vrže kost za glodanje:

Kar nas drži v našem bistvu, nas seveda drži le toliko dolgo, kolikor sami ob-držimo to držeče. Ob-držimo ga, če ne zapušča pomnenja. Pomnenje je zbranost mislenja. Za kaj pa? Za to, kar nas drži, kolikor nanj pomislimo, pri

10 Prim. Derrida, 2000.

11 Podrobneje o smiselnih premenah besede »Wesen« v razvoju Heideggerjeve misli: gl. Komel, 1997.

12 V zvezi s tem napotujem na: Bednarik, 2003. 
sebi, pomislimo namreč zato, ker o n o [Es] ostaja to, kar je treba pomisliti. Spomisleno je z zmislenjem obdarjeno, obdarjeno je, ker ga maramo [mögen]. Le kolikor maramo to, kar je v sebi tisto, kar je za spomisliti, zmoremo [vermögen] misliti (Heidegger, 2017, 11).

Treba se je zadržati pri okoliščini, da je že v tem uvodnem nagovoru glede spomina in misli govor o "pomnjenju«, zraven pa se pritakne še »zmislenje«, ki smo ga omenili že prej ob Hölderlinovi pesnitvi Andenken, pa še o novotvorjenki »spomislenje« kot prevedenki za nemško besedo »das Bedachte«. Običajna nemška beseda za spomin oz. pomnjenje "Erinnerung« tu sploh ne nastopa, v celotnem delu pa samo dvakrat. Heideggerju tudi ni do tega, da bi pojmovni kontekst nemških besed za izražanje spomina naredil »jasen in razviden«, pač pa mu rabijo izključno za to, da prikličejo neko jasnino v odnos spomina in misli. Tako na ključni točki premisleka razmerja med spominom in mislijo spomni na staronemško besedo Gedanc, ki smo jo v slovenščino "preložili« z besedo "pomislenie« iz Brižinskih spomenikov. ${ }^{13}$ To seveda vnaprej napotuje k pomisleku, da je nemara govorica oz. govorice ta, ki v sebi »čuva« tako spomin kot misel. Niso redki, ki bi temu ugovarjali, ob čemer velja opomniti, da je Platon zapis govora v dialogu Fajdros izrecno označil za torišče pozabe. ${ }^{14}$ Verjetno je ob Platonu precej tistih, ki bi se, zdi se, da povsem upravičeno, obregnili ob to, da zmožnosti mišljenja in spominjanja, ki imata osrednjo veljavo ne le v filozofiji, marveč povsod, kjer gre za spoznavanje in znanje, obravnavamo na osnovi pomenov, ki so ohranjani v besedah, celo takšnih, ki so že zdavnaj iz rabe.

No, v enaki meri bi bilo treba pomisliti, kako to, da ravno govorica hrani misel in spomin, saj ni pomnilnik. Recimo, če pravimo »bistvo«, kako sta v tej besedi ohranjena spomin in misel? Ker je to oznaka $z$ določenim pomenom? Se pravi neki pojem, ki naj bi besedo zajel tako, da ji podeli določnost? Malo prej se je izkazalo, da pomen besede »bistvo« sploh ni določno obmejen. Zdi se celo, da je njen pomen naposled odvisen le od tega, kaj z njo vsakokrat menimo. »Menjenje« in "pomenjanje« so storitve govora kot mnenja. A filozofija kot pojmovno mišljenje naj bi ravno ne p(r)odajala mnenja - doxe, marveč logos kot tisto celoto govora (stavek, sodba, izjava), ki izreka resnico, hkrati pa lahko tudi podleže laži.

Če se govorjeno ne le kot menjeno, marveč tudi kot resnično menjeno tako razkriva kot prikriva, kako naj govorica izvorno hrani spomin in misel? Mar to ne

13 Velja poudariti, da se je besedilo Brižinskih spomenikov izkazalo kot izjemno dragocen vir, ne le v smislu vzdrževanja spomina na začetke nekega jezika, marveč tudi, če lahko rečemo, "pojmovne konsistentnosti«, ki razodeva (predhodno) filozofsko razumevanje in bi ga bilo treba kot takega sistematično rekonstruirati. V kontekstu tega razpravljanja je poleg besede "pomislenje« gotovo najzanimivejša beseda "zimizla « v pomenu »smisel «, "zavest«, »sensus« (Slovar besedja brižinskih spomenikov, http://nl.ijs.si/e-zrc/bs/html/bsLX.html).

14 Prim. k temu: Grilc, 2001, 71-92. 
zahteva, da se od logosa odmaknemo nazaj k mythosu. Ne nazadnje se lahko vzorujemo pri Platonovem dialogu Kratil. Starogrška beseda mythos ima isti etimološki koren kot slovenska beseda »misliti« ( ${ }^{*} m e u d^{h-}$ "paziti na«, "misliti na«). Če to združimo še $\mathrm{z}$ utečenim razumevanjem mita kot »kolektivnega spomina«, si lahko že domišljamo, da smo, če se podamo od logosa nazaj k mythosu, na pravi poti, da ugotovimo, kako je z izvornim odnosom med mislijo in spominom. Manjka samo še pridati, da podobno ravna tudi Heidegger. Vendar ne gre za to, da že morda njegov slog razmišljanja spominja na to, pač pa vprašanje sopripadanja bistvenih odnosov, ki nas tu zaposlujejo, takole zastavi:

Kaj je imenovano z besedami 'Denken', 'mislenje', 'Gedachtes', 'misleno', 'Gedanke', 'misel'? V katero področje govorjenega napotujejo? Gedachtes, misleno - kje je, kje ostaja? Potrebuje Gedächtnis: pomnenje, spomin. K mislenemu in njegovi misli, 'Gedanc', 'pomislenie', spada Dank, zahvala. Morda so ta odzvanjanja besede 'Denken' ob Gedächtnis in Dank le površno in umetno izmišljena. $\mathrm{S}$ tem še nikakor ne posveti, kaj je imenovano z besedo 'misliti'.

Je mislenje zahvalnost? Kaj tukaj pomeni zahvalnost? Ali zahvala počiva [beruht] v mislenju? Kaj tu pomeni misliti? Je pomnenje le vsebnik za misleno mislenja ali pa mislenje samo počiva $\mathrm{v}$ pomnenju? Kako se zahvala obnaša do pomnenja? Ko tako sprašujemo, se gibljemo v prostoru govorjenega, ki nas nagovarja $\mathrm{z}$ glagolom 'misliti. Vse odnose med imenovanimi besedami 'Denken', 'Gedachtes', 'Gedanke, 'Dank', 'Gedächtnis' - 'mislenje, 'misleno', 'misel', 'zahvala, 'pomnenje' puščamo odprte. Pa povprašajmo pri zgodovini teh besedi. Ta nam daje napotilo, četudi je zgodovinopisni prikaz te zgodovine še nepopoln in bo tak tudi ostal.

Sprejemamo napotek, da se $\mathrm{v}$ govorjenem imenovanih besedi merodajno in izvorno upovedovalna beseda glasi 'Gedanc', 'pomislenie'. Ne pomeni pa tistega, kar zdaj kot zadnje še preostane $\mathrm{v}$ utečenem pomenu današnje rabe besede 'misel'. Misel običajno pomeni: ideja, predstava, mnenje, domislek. Začetna beseda 'Gedanc', 'pomislenie' pove: zbrano, vse zbirajoče Gedenken, spomislenje, pamet(enje). 'Der Gedanc' pove toliko kot das Gemüt, čud, der mout, srce (Heidegger, 2017, 121-122).

Odnos med mislijo in spominom Heidegger s pomočjo starovisokonemške besede Gedanc, pomislenie, zastavi iz vzajemne vznesenosti z zahvalnostjo (Dank). Lahko rečemo, da se Dank tu vplete zgolj zaradi besednega sozvočja z Denken. Kaj pa, če je v zahvali sami prisotno sozvočje, ki uglasi misel in spomin? Morda iz njunega uglaševanja nastopi ubranost zahvalnega? V uglaševanju, zvenenju, zvočnosti in ubranosti govori govorica. Reči »širijo se glasovi« je isto kot reči »širijo se govorice«. 
Vendar je govorici morda še bolj kot širjenje na način glasovnega razleganja notranje lastno, da skriva govorjeno. Skriva pomeni: čuva, ohranja, varuje. Kam? V skrivnost svojega bistva in vsega, kar se je mogoče spomniti ter spominja na. Da ostaja sled skrivnosti, ne izhaja v prvi vrsti in sploh ne iz spominjanja, marveč iz pozabe, če jo razumemo, da "prihaja v skritost $«{ }^{15}$ To velja posebej spomniti in pomniti, saj krije nagovor, ki da misliti, oziroma ji podari zbranost misli. »Zbranost misli« je bistveno zmislenje. Nagovorjena je od bistvene podarjenosti, ki se ji lahko samo zahvalimo za dogodevanje našega bistva. Zahvalnost ni zgolj to, kar lahko izrazimo nekomu, marveč sama najneposrednejše izpoveduje naše notranje bistvo, naše »bitje in žitje«.

$\mathrm{S}$ tem ko Heidegger $\mathrm{v}$ ta odnos vplete izpovedovanje zahvalnosti (Dank), se hkrati prebudi čud kot notranje bistvo, notrinskost (Innigkeit), hram spomina, na kar napotuje tudi nemška beseda Erinnerung, spomin kot ponotranjenje. Misel in spomin sta si notri tako, da si izkazujeta vzajemno zahvalnost za bistveno. Tudi v tem primeru vstopi vmes »izkazovanje« in »izpovedovanje« kot govorica. Nujna soizpoved kaže prisotnost bistvenega. Le tam, kjer prisostvuje bistveno, sta hvaležnost in posvečenost. Prisotnost bistvenega se Heideggerju izkazuje kot Andacht, "pomnost«, beseda, s katero podkrepi vpeljavo starovisokonemške besede Gedanc:

Vendar beseda 'Gedanc' ne meni le tega, kar imenujemo čud in srce in komajda izmerimo $\mathrm{v}$ njegovem bistvu. V Gedanc tičita in bistvujeta pomnenje in zahvalnost. 'Gedächtnis', 'pomnenje', začetno nikakor ne pomeni zmožnosti spominjanja [Erinnerungsvermögen]. Beseda imenuje celotno čud v smislu stalnega notrinskega zbiranja ob tem, kar bistvenostno spregovarja vsem čutom. Das Gedächtnis izvorno pove toliko kot An-dacht, 'pomnost': nenehno, zbrano ostajanje-ob ... in sicer ne zgolj ob preteklem, temveč enako ob pričujočem in tem, kar lahko pride. Preteklo, pričujoče, prihajajoče se prikažejo $\mathrm{v}$ enotnosti nekega vselej lastnega pri-sostva [An-wesens] (Heidegger, 2017, 121).

$\mathrm{V}$ nemščini se beseda "Anwesen « (prisotnost) opira na isti glagol kot beseda »Wesen« (bistvo). V slovenščini je zaradi različnih glagolskih osnov »Bistva« in "prisotnosti« možno izrekati tako »bistvena prisotnost « kot »prisotnost bistvenega Tako kot prva ne pomeni navzočnosti, tako druga ne pomeni le obstojnosti, marveč: pričujočnost kot čuječnost, ki stremi k bistvenemu in je čudežna odlika čudi. Heidegger jo zajame z besedo Andacht, ki se je sicer "pritihotapila « tudi v slovenščino. ${ }^{16}$

15 V tem pogledu je zanimiva raba glagolov lanthano (sem skrit, pozabljen, ostanem neopažen) in epilanthanomai (pozabim kaj, zamolčim) pri Heraklitu.

16 Slovenski prevod »pomnost « se opira na rabo te besede v duhovnostnih praksah. Na slovensko izposojenko sem prvič postal pozoren, ko sem od Mete Kušar slišal, češ kako so nekateri ljudje »brez andahta«. Natančen opis javljanja »Andacht « v slovenščini podaja Jazbec, 2007, 27: »andohtliu (4) adj. 'pobožen' - Sln. andohtljiv je izsamostalniški pridevnik k sln. Andoht, 'pobožnost'. V Trubarjevem 
Kolikor Gedächtnis, pomnenje, kot zbranost čudi, kot An-dacht, pomnost, ne od-pusti tega, na čemer in na kar [worauf] se zbere, v pomnenju ne vlada samó poteza bistvenostnega zmislenja na nekaj, ampak obenem s tem poteza ne odpuščajočega in ne opuščajočega ohranjanja. Duša nato iz pomnenja in znotraj njega izseva zaklad podob, tj. pogledov, od katerih je sama ugledana. Šele od tu se znotraj širno in globoko zajetega bistva pomnenja, vz-diguje obdržanje nasproti izmuznjenju, kar Latinci poimenujejo memoria tenere. Obdrževanje v memoria se navezuje tako na preteklo kot tudi na pričujoče in prihodnje. Obdrževanje zaposluje predvsem preteklo, ker je od-šlo in nekako ne ponuja več ničesar obdržljivega. Zato se smisel obdržanja za tem omeji na preteklo, ki ga pomnenje vselej znova prinaša na plano. Kolikor ta omejeni odnos izvorno ne tvori edin(stven) ega bistva pomnenja, se primeri reklo: (s)pomnenje - imenuje posebno obdrževanje in ponovno-prinašanje preteklega.

V začetni besedi 'der Gedanc' vlada izvorno bistvo pomnenja: zbranost neprenehnega menjenja vsega tistega, kar čud pusti prisostvovati. Meinen, menjenje, je tukaj razumljeno $\mathrm{v}$ pomenu minne, 'ljubáv': naklonjenost najnotrišnjega čuta čudi do bistvujočega, ki sebe ne obvladuje in je zato nujno in izrecno še ni moč izpolniti (Heidegger, 2017, 122).

Filozofija, »odkar pomni«, razlikuje med »misliti« in »meniti«. Vendar pa razlikovanje hkrati obeležuje to, da »misliti« bistveno izpolnjuje »spomniti« in "pomniti« ter je v tem smislu zmenjeno z menjenjem kot svojo lastno strastjo. Ta lahko skrepeni v "prazno mnenje«, lahko pa prebudi duhapolno pomnjenje, ki vzdržuje zbranost mislenja kot zmislenja na najpomiselnejše.

besedilu se pojavlja kot lastnost človeka, molitve kot dejanja ali kot lastnost človeškega srca. Nastopa tudi ob svojem sinonimu brumen. Po H. Striedter-Tempsovi je izposojeno iz srvn. andaht. Nemška beseda je v 12. stoletju dobila pomen 'zavestno posvečanje misli Bogu, božjemu', Lexer-Pretzel, 4, navajata tudi 'pokora, kazen'. Prej je bil njen pomen bolj splošen: 'zavestno posvečanje misli nekemu cilju' Tudi do izposoje je moralo priti v 12. stoletju, saj bi bile po letu 1200 vidne sledi bavarske labializacije a-ja v o (prim. pri almoshna in altar). Po mnenju H. Striedter-Tempsove je -ov sln. andoht slovenski razvoj, v ilustracijo navaja tudi sln. gradivo z -a- (andaht) (ST 81). Gre za narečni razvoj sln. dolgega a v o, ki se pojavlja na raznih krajih, med drugim tudi na zahodnem dolenjskem robu (Ramovš, 1995, 223). Ta slovenski razvoj časovno umeščajo v 12./13. stoletje (Logar, 1996, 333), kar še dodatno potrjuje čas izposoje v 12. stoletju. Glede na to, da je bil srvn. $a$ v drugem zlogu and-a-ht dolg, je namreč zelo verjetno, da smo ga substituirali s slovenskim dolgim vokalom, ki je potem doživel omenjen razvoj. N. Godnič-Godini navaja sodobno kraško and'ht 'obred, svečanost, zbranost' (1981, 142). Pridevnik andohtljiv je tvorjen po nemškem zgledu srvn. andeeht-ec adj. 'pobožen' vendar z domačimi besedotvornimi sredstvi, tj. s pripono -ljiv. Nvn. Andacht 'verska zatopljenost, krajša molitev', srvn. andaht 'misel na Boga, predanost Bogu', stvn. anathaht 'misel na nekaj, pozornost, predanost' je abstraktum, izpeljan iz stvn. glagola anathenken 'misliti na nekaj', ki je predponska izpeljanka iz stvn. thenken 'razmišljati', germanskega glagola na -jan (Pfeifer, 39, 214).« 


\section{Bibliografija}

Aristoteles, Metafizika, Ljubljana 1999.

Bednarik, J., Smisel šibkosti. Oris filozofske misli Giannija Vattima, Ljubljana 2003.

Derrida, J., O duhu. Heidegger in vprašanje, Ljubljana 2000.

Grilc, U., Filozofija pisave. Na poti k Derridaju, Ljubljana 2001.

Grgić, F., Aristotelovo to ti en einai u svjetlu tumačenja Metaph. Z 4-6, Filozofska istraživanja 10/4, 1990, str. 1003-1023.

Heidegger, M., Bit in čas, Ljubljana 1997.

Heidegger, M., Kaj se pravi misliti, Ljubljana 2017.

Heidegger, M., Razjasnjenja ob Hölderlinovem pesništvu, Ljubljana 2001.

Hölderlin, F., Hölderlin, (prev. N. Grafenauer), Ljubljana 1978, (Lirika; 41).

Husserl, E., Phantasie, Bildbewusstsein, Erinnerung. Zur Phänomenologie der anschaulichen Vergegenwärtigungen, Husserliana XXIII, Haag, Boston, London 1980.

Husserl, E., Filozofija kot stroga znanost, Ljubljana 1991.

Husserl, E., Fenomenološka arheologija, Phainomena 51-52, 2005, str. 5-8.

Jazbec, H., Nemške izposojenke pri Trubarju na primeru besedila Ena dolga predguvor, Ljubljana 2007.

Komel, D., Filozofski prevod kot pot do govorice, Phainomena 21-22, 1997, 81-93.

Komel, D., Pripis k slovenskemu prevodu »Kaj se pravi misliti«, v: Heidegger, M., Kaj se pravi misliti, Ljubljana 2017, str. 237-242.

Komel, D., Martin Heidegger: Kaj se pravi misliti, Phainomena 104/105 (2018), str. 329-345.

Nietzsche, F., Vesela znanost, Ljubljana 2005.

Ricoeur, P., La mémoire, l'histoire, l'oubli, Pariz 2000.

Sonderegger, E., Die Bildung des Ausdrucks to ti ēn einai durch Aristoteles, Archiv für Geschichte der Philosophie 65, 1983, str. 18-39.

Zor, J., Jakopin, F., Logar, T., Slovar besedja brižinskih spomenikov, http://nl.ijs.si/e-zrc/ bs/html/bsLX.html [19. 10. 2017]. 


\section{Dean Komel}

\section{Spomin in pomnjenje $v$ Heideggerjevi obravnavi vprašanja o tem, kaj se pravi misliti}

Ključne besede: spomin, pomnjenje, mislenje, Heidegger, govorica, bistvo

Filozofija vprašanje o možnosti spoznanja od svojih začetkov povezuje $\mathrm{z}$ zmožnostjo spominjanja. Novejša filozofija, začenši s Kierkegaardom, spominjanje pritegne na način omogočanja gibanja človeške eksistence v svetu. Martin Heidegger je v freiburških predavanjih v letih 1951/52, ki so leta 1954 izšla v delu Kaj se pravi misliti?, obravnaval spomin in pomnjenje $\mathrm{v}$ pogledu sopripadnosti mislenja in biti. Podrobnejša razčlenitev njegove obravnave nam pokaže »breztemeljni izvor« spominjanja in pomnjenja, ki je sam po sebi položen v govorico in z njo. Govorica potemtakem izvorno »hrani« in »ohranja« spomin. Vendar v času, v katerem po Heideggerju »še ne mislimo«, istočasno pa ga zaznamuje razmah kognitivne tehnologije, tvegamo, da gre ravno govorica v pozabo, ne da bi kakorkoli občutili nujo, da (se) na to spomnimo. 


\section{Dean Komel}

\section{Remembrance and Memory in Heidegger's Discussion of the Question What Is Called Thinking}

Keywords: remembrance, memory, thinking, Heidegger, language, essence.

From its very beginning, philosophy linked the question of the possibility of cognition with the ability of remembrance or recollection (anamnesis). Contemporary philosophy, starting with Kierkegaard, considers remembrance as a way of enabling the movement of human existence in the world. In his Freiburg lectures from 1951/52, published in 1954 under the Title What Is Called Thinking?, Heidegger addresses remembrance and memory in terms of the correspondence between thinking and being. A detailed analysis of his treatise reveals the "groundless origin" of memory, which is of itself placed in language and with it. Language, thus, originally "keeps" and "preserves" memory. However, in a time in which, according to Heidegger, "we do not yet think", but is also denoted by the expansion of cognitive technologies, language is threatened by falling into oblivion, without us ever noting the need to remember this circumstance. 